\title{
RESPONSABILIDADE PENAL DA PESSOA JURÍDICA NA CHINA: LEGISLAÇÃO E SUAS DEFICIÊNCIAS
}

\author{
CORPORATE CRIMINAL LIABILITY IN CHINA: LEGISLATION AND ITS DEFICIENCY
}

\section{Zhang Yingjun*}

\begin{abstract}
Resumo:
A punição da pessoa jurídica na República Popular da China é tema relativamente novo. Dado o sistema de organização da economia política chinesa, até 1978, a situação foi contornada pelo Código Penal revisado, sob a rubrica "Crimes Cometidos por uma Corporação", caracterizando-se a responsabilidade penal da pessoa jurídica chinesa pelo sistema de dupla imputação imposto à corporação e à pessoa física responsável pelo crime. Atualmente há no Direito Penal chinês apenas um tipo de sanção pecuniária que pode ser imposto à pessoa jurídica que comete crime, ao passo que outras sanções como o encerramento das atividades da companhia ou a exclusão na participação em aquisições, podem ser impostas na forma de sanções administrativas em consonância com as normas administrativas. A responsabilidade criminal corporativa demanda princípios mais precisos e detalhados na legislação penal chinesa. Infelizmente, este grau de precisão e detalhamento ainda não foi alcançado pelo Direito Penal chinês. As regras relativas à atuação de empresas multinacionais também são enfrentadas no artigo.
\end{abstract}

Palavras-chave: Direito Chinês. Direito Penal. Responsabilidade da Pessoa Jurídica. Criminalidade Empresarial.

\begin{abstract}
:
The criminalization of corporate crimes committed by legal entities is not a tradition in the legal system of the People's Republic of China. Due to the special situation in China, until 1978, the case was covered by the revised Code of Criminal Law as "Crimes Committed by a Unit". This Chinese way of corporate criminal responsibility is featured by the "Double Punishments" imposed both on the corporation that commits a crime and the people who are directly in charge and responsible for the crime. Nowadays, in Chinese Criminal Law, only one kind of monetary penalty (fine) can be imposed to the corporation that commits a crime, whereas the other penalties such as disclosure of the companies, suspending from some business operations and exclusion from participation in a procurement, all can be imposed as administrative sanctions by the authorities, according to related administrative acts and regulations. As attributable liability, corporate criminal responsibility requires more precise and detailed principles of attribution in the
\end{abstract}

Professora Associada da Faculdade de Direito da South-Central University for Nationalities, Wuhan, República Popular da China; BA, Wuhan University, China, 1990; L.L.M, Wuhan University, 2003; Doutora em Direito pela Wuhan University, 2006. Este artigo baseia-se em pesquisa realizada como parte de Projeto financiado pela The Chinese National Foundation for Social Science sobre o tema "The Legal Issues of International Law on the Transnational Corporate Offences" (n. 08BFX074). A autora agradece ao Prof. Dr. Rafael Diniz Pucci (Universidade de São Paulo) pela recomendação e tradução do artigo. Correio eletrônico: zyj2161@sina.com. 
national criminal law. Unfortunately, this degree has not been archived in Chinese Criminal Law yet. The rules related to the corporate criminal liability are also analysed.

Keywords: Chinese Law. Criminal Law. Corporate Liability. Corporate Crime.

\section{Responsabilidade penal coletiva na República Popular da China}

A criminalização de desvios cometidos por corporações ou pessoas jurídicas não é tradição chinesa, fato que remonta ao estabelecimento da República Popular da China em outubro de 1949. Isto em virtude da escolha de se organizar a economia através do planejamento estatal, fato que predominou até 1978, com o início das reformas de abertura econômica.

Naturalmente, até 1978, as pessoas jurídicas não eram autorizadas a agirem de forma independente do Estado. Ao contrário, o Estado mesmo intervinha diretamente na economia, criando e gerindo as empresas e, consequentemente, não havia espaço para a punição da pessoa jurídica, motivo pelo qual o Código Penal da República Popular da China, de 1979, não fez previsão a respeito.

Com a reforma econômica, gradualmente iniciou-se uma clivagem entre as empresas e as "unidades". Neste ínterim, com a previsão da existência de setores privados autorizados, o capital privado passou a atuar no mercado. Como resultado, companhias privadas, joint ventures estrangeiras, sociedades empresárias de capital aberto, sociedades limitadas e outras formas de organização começaram a emergir e, assim, também os crimes cometidos pelas corporações começam a sofrer sistemático incremento.

A partir de 1997, com a reforma da legislação penal chinesa, passou-se a criminalizar os crimes empresariais, notadamente aqueles cometidos por propriedades independentes e de responsabilidade limitada, cuja proporção é menor do que a da "unidade" ou das "organizações".

Na China, os conceitos de "unidade" e "organização" apresentam conteúdo mais abrangente do que nos países ocidentais.

“Organização" significa, em termos gerais, coletividade do setor privado, mesmo aquelas organizadas com baixo grau de institucionalização. "Unidade”, por outro lado, é conceito que inclui não apenas empresas, instituições e organizações, mas também coletividades do setor público.

Aliás, a criminalização da "unidade" parece ser a melhor alternativa na China, já que não raro as coletividades do setor público também praticam condutas nocivas a bens jurídicos, mas há divergências doutrinárias quanto à possibilidade de punição das "unidades". Assim, o Capítulo IV Parte Geral da Reforma Legislativa Penal de 1997, é 
intitulado "Crimes praticados pela unidade", e não, por exemplo, "Crimes cometidos por corporações". Desta forma, os crimes praticados pela "unidade" compreendem os crimes empresariais.

Além disto, há sanções administrativas, com larga margem de discricionariedade para que a administração pública puna a empresa que infrinja regras administrativas.

Além da Parte Geral da Reforma Legislativa Penal de 1997, também as decisões ou, em sentido estrito, as interpretações da Suprema Corte chinesa são importante referência para a aferição da responsabilidade da pessoa jurídica na China, ainda que não sejam consideradas fontes do direito no sistema chinês. Assim, a Interpretação n. 17/1999, deixa patente a possibilidade de a Suprema Corte interpretar e, em certo sentido, criar regras, em matéria da sanção penal das "unidades". De igual maneira, a Interpretação n. 31/2000 é esclarecedora ao sustentar a dupla imputação da "unidade" e da(s) pessoa(s) física(s) envolvida(s) na conduta.

Passa-se, aqui, à enumeração das características fundamentais que normatizam a imputação penal da pessoa jurídica na China, esclarecendo-se, ainda, suas deficiências.

1.2. Legislação sobre Responsabilidade Penal da Pessoa Jurídica - Disposições do Direito Penal da República Popular da China

Os arts. 30 e 31 da Parte Geral da Reforma Legislativa Penal de 1997 preveem a criminalização da pessoa jurídica, nos seguintes termos:

Art. 30. Qualquer companhia, empresa, instituição, órgão estatal ou organização que pratique conduta que coloque em risco a sociedade, conduta esta descrita em lei como crime praticado pela unidade, deve ser responsabilizada criminalmente.

Art. 31. Quando a unidade comete um crime, deve ela ser multada, e as pessoas encarregadas ou outras pessoas que são diretamente responsáveis pelo crime devem ser punidas criminalmente. Quando em outras normas haja alguma disposição específica, elas devem prevalecer.

Na Parte Especial da Lei Penal da República Popular da China, após oito alterações legislativas, o número de tipos penais relativos à punição da "unidade", foi incrementado para 124. De acordo com a última reforma, os tipos podem ser encontrados principalmente no capítulo relativo aos crimes de perturbação da ordem socialista 
de mercado ${ }^{1}$ e no Capítulo VI que trata de "Crimes contra a Administração da Ordem Pública", ${ }^{2}$ assim como previsões contidas em outros artigos esparsos da Lei. ${ }^{3}$

\subsection{Responsabilidade penal corporativa nas interpretações judiciais}

Consoante retromencionado, a jurisprudência, embora não represente fonte em sentido estrito, tem um papel importante na construção da responsabilidade penal corporativa no sistema penal chinês. Neste sentido, especialmente a Interpretação da Corte Suprema n. 17/1999 e a Interpretação n. 31/2000 exercem relevante função.

Em primeiro lugar, analisaremos (A) as Disposições relativas à aplicação da Lei Penal de 1997 para casos envolvendo a responsabilidade das "unidades" (Informativo n. 17/1999).

Neste mister, é preciso sublinhar as seguintes conclusões da Corte Suprema: (i) As companhias, empresas e instituições contempladas no art. 30 da Lei Penal de 1997 não incluem apenas coletividades, companhias e empresas do estado ou da iniciativa privada, mas também outras formas a exemplo de joint ventures, cooperativas e outras pessoas jurídicas; (ii) Os crimes cometidos por coletividades adrede constituídas para a prática de ilícitos sofrem imputação diversa daquela registrada para as "unidades"; (iii) Caso uma pessoa física cometa crime atuando em nome da "unidade", mas sem consentimento para fazê-lo, deve ser punido de acordo com as regras e tipos penais relativos a crimes cometidos pelas pessoas físicas. ${ }^{4}$

Em segundo lugar, observam-se as disposições $(\mathrm{B})$ relativas às pessoas físicas envolvidas na conduta praticada pela "unidade", em atenção ao sistema de

Este capítulo, da segunda parte da Parte Especial, consiste de 8 Seções, dos arts. 140 ao 231, a incluir 110 tipos penais, como os Crimes de Produção e Comercialização de Mercadorias Falsificadas (Seção 1); Crimes de Contrabando (Seção 2); Crimes contra a Administração de Companhias e Empresas (Seção 3); Crimes contra a Administração Financeira (Seção 4); Crimes de Fraude Financeira (Seção 5); Crimes de risco à administração da arrecadação de impostos (Seção 6); Crimes contra a Propriedade Intelectual (Seção 7); Crimes contra a ordem econômica (Seção 8). Na maior parte destes tipos penais a "unidade" pode ser responsabilizada.

2 Este capítulo consiste de 9 Seções, do art. 277 ao art. 367, incluindo 120 tipos penais, contemplando os Crimes contra a ordem pública (Seção 1); Crimes de dano à administração da justiça (Seção 2); Crimes contra o controle da fronteira nacional (Seção 3); Crime contra o controle das riquezas culturais (Seção 4); Crimes de dano à saúde pública (Seção 5); Crime de dano ao meio ambiente e aos recursos naturais (Seção 6); Crimes de contrabando, tráfico, transporte e produção de narcóticos (Seção 7); Crimes de aliciamento de pessoas para a prostituição (Seção 8); Crimes de exploração de material pornográfico (Seção 9). Apenas em alguns destes tipos pode a "unidade" ser responsabilizada.

3 Dois tipos penais relativos à responsabilização penal da "unidade" foram incluídos pela última reforma da Lei Penal chinesa, a saber: art. 205 (a), falsificação de marcas; art. 276 (a), inadimplemento malicioso de remuneração.

4 Cf. Disponível em: <http://www.law-lib.com/law/law_view.asp?id=460>. Acesso em: 3 out. 2011. 
dupla imputação (Informativo n. 31/2000). Neste aspecto, a Suprema Corte define que independentemente de ser partícipe ou coautora, a pessoa física também deve ser punida. ${ }^{5}$

1.4. Responsabilidade penal corporativa segundo os documentos da Instituição de Pesquisa da Suprema Corte da China

Os documentos de interpretação da Suprema Corte, como já mencionado, têm importante papel para a práxis jurídica, notadamente no que concerne à responsabilização penal corporativa. Neste sentido, o órgão de pesquisa da Suprema Corte estabeleceu que corporações estrangeiras cujas condutas ofendam bens jurídicos, colocando em perigo a sociedade chinesa, devem ser punidas de acordo com as normas relativas à punição penal das "unidades".

No entanto, as condutas praticadas por pessoas físicas ou jurídicas estrangeiras, que deliberadamente foram constituídas para a prática de ilícitos no território da República Popular da China, são punidas com outras regras, que não aquelas aplicadas à punição penal das "unidades".

\section{Tipos de crimes corporativos no Direito Penal chinês}

A Parte Especial da Lei Penal da República Popular da China dispõe de 124 tipos penais que podem ser praticados pelas "unidades". Podemos classificá-los em dois sistemas: 2.1. Crimes de Imputação Simples; 2.2. Crimes de Dupla Imputação, a saber:

\subsection{Crimes de Imputação Simples}

A Lei Penal chinesa faz referência aos crimes de imputação simples, que apenas podem ser praticados pelas "unidades", não podendo sê-lo por pessoas físicas. $\mathrm{O}$ art. 327 da Lei Penal preceitua, neste sentido, que a venda não permitida de riquezas culturais, praticada por "unidade" pertencente ao Estado, a exemplo de museus ou outras instituições congêneres, sujeita a pena privativa de liberdade de até três anos ou detenção. Além disto, a hipótese também pode ser encontrada no art. 387, que se refere a crimes de aceitação de suborno praticados por "unidades" ou também no art. 393, que disciplina a hipótese da oferta de suborno.

Cf. Disponível em: <http://www.lawtime.cn/info/xingfa/fzdwfz/2011021411629.html>. Acesso em: 10 out. 2011. 


\subsection{Crimes de Dupla Imputação}

Os crimes de dupla imputação podem ser praticados tanto por "unidades" quanto por pessoas físicas.

Grande parte dos tipos penais previstos na Parte Especial do Direito Penal Chinês, na realidade, estão classificados nesta espécie. As pessoas físicas envolvidas, em regra, são punidas a partir dos mesmos pressupostos pelos quais são punidas as pessoas encarregadas da administração de uma "unidade”. O art. 187 da Lei Penal, neste sentido, prevê que o funcionário de um banco envolvido em ilícito penal da instituição financeira está sujeito a pena privativa de liberdade de até 5 anos, além de multa; para a unidade, prevê-se a multa. Para a hipótese de lavagem de dinheiro, prevê-se que a pessoa física seja apenada com pena privativa de liberdade que varia de 5 a 10 anos, sendo aplicada à "unidade" a pena de multa. ${ }^{6}$

\section{As Características da Responsabilidade Criminal Corporativa na China}

É possível, portanto, do quanto mencionado, extrair-se as conclusões a seguir:

(i) Quanto ao sujeito ativo de crimes corporativos, a espécie "unidade" contempla qualquer companhia, instituição, empresa, órgão estatal ou organização, em consonância com o art. 30 da Parte Geral da Lei Penal chinesa de 1997.

Resta, portanto, a discussão sobre a possibilidade de punição do órgão estatal. Ora, punir o órgão estatal seria espécie de self punishment, o que, para alguns, não soa razoável. No entanto, é preciso que se considere o fato de que o aparato estatal, ao praticar atos previstos na Lei Penal, está colocando em risco bens jurídicos caros à sociedade. Neste sentido, afigurar-se-ia importante a punição de tais atos, a contemplar, eventualmente, em sede de dupla imputação, o próprio agente público encarregado do ato ilícito.

(ii) Quanto ao sistema de responsabilidade baseado na dupla imputação, é preciso que se considere a responsabilização tanto da "unidade" quanto dos executivos responsáveis pela prática das condutas consideradas como ilícito penal, o que vem estabelecido no art. 31 da Lei Penal chinesa de 1997.

CF. NATIONAL PEOPLE'S CONGRESS OF THE PEOPLE'S REPUBLIC OF CHINA. Disponível em: $<$ http://law.npc.gov.cn:87/>. Acesso em: 3 out. 2011. 
Para a "unidade", aplica-se a pena de multa; para as pessoas físicas encarregadas dos atos ou outros eventuais partícipes ou coautores, o caso é de aplicação também de multa, combinada com pena privativa de liberdade.

Até o momento, apenas a pena de multa pode ser imposta à "unidade". As demais sanções como interrupção de atividades, interrupção de financiamento e outras operações negociais, são impostas pela administração pública, na forma de sanção administrativa.

A bem da verdade, o referido art. 31 estabelece uma exceção: caso exista algum ato normativo específico, pode haver a punição a título penal da "unidade", fora das hipóteses até agora alinhavadas. Naturalmente, este fato abre margem para que corporações venham a ser punidas a partir da edição de eventual ato a excepcionar a aplicação da Lei.

4. As Deficiências da Legislação relativa à Responsabilidade Criminal das Corporações

Resta, pois, analisar algumas questões em que parece haver lacunas normativas. Ou seja, visto de outra perspectiva, podemos buscar quais são as falhas da regulamentação chinesa no que tange a desvios cometidos pelas corporações, de modo a prejudicar bens jurídicos.

(a) Quais são as pessoas cujos atos podem ser punidos por praticar ilícito penal ao lado da "unidade"? O art. 31 da Lei Penal estabelece que são as pessoas encarregadas da "unidade" ou mesmo que diretamente concorrem para o crime. No entanto, resta o fato de que, quando se confronta a estrutura de uma organização, muitas vezes a responsabilidade se dilui, tornando-se difícil imputar concretamente responsabilidades.

Na prática, isto tem dificultado a punição de pessoas, à medida que se torna muito dificultosa a prova do cometimento do ilícito.

(b) Que tipos de conduta podem ser definidas como crimes cometidos por uma "unidade"? Esta resposta pode ser encontrada nas Interpretações da Suprema Corte Chinesa, especialmente no texto da Interpretação n. 17/1999. O parágrafo III da Interpretação sugere que caso a pessoa física tenha atuado em nome da "unidade", sem, no entanto, ter poderes para tanto, deve ser punida de acordo com as regras gerais da Lei Penal, e não de acordo com as regras específicas relativas à punição das corporações que cometem ilícitos penais. Há interpretação realizada por painel de discussão da Suprema Corte no que tange a casos relativos a crimes financeiros, no sentido de que na hipótese 
de agir em nome da "unidade" e com poderes para tanto, deve ser punida, em raciocínio a contrario sensu. ${ }^{7}$

Portanto, do exposto, é possível inferir que para ser punida a pessoa física deve ter agido em nome da "unidade" e deve ter obtido proveitos para aquela "unidade". Ocorre que a prova é extremamente dificultosa, já que em operações complexas não é fácil externar o caminho percorrido, por exemplo, por algum ato de corrupção; em outras palavras, afigura-se difícil provar que houve a obtenção de proveito para a "unidade". Há casos em que interesses escusos ou mesmo invisíveis, por exemplo, quando o ato ilícito se deu em proveito não financeiro diretamente, mas ligado a algum incremento do status empresarial, da imagem da "unidade" ou prospecção de novos negócios. Provavelmente tais vantagens se tornarão visíveis no futuro; no entanto, no momento da investigação, afigura-se extremamente dificultosa a prova do requisito "proventos ilícitos obtidos para a unidade". Ao menos os termos do tipo penal poderiam ser aperfeiçoados.

Assim, os critérios de imputação da responsabilidade criminal corporativa estão a demandar, no sistema chinês, maior precisão e princípios com conteúdo mais detalhado, notadamente no que concerne à persecução penal, de modo a assegurar imparcialidade de julgamentos e combate efetivo aos crimes corporativos.

Idealmente, a construção de regras deve se dar no âmbito legislativo e não no âmbito de inovação jurisprudencial com interpretações ou documentos da Suprema Corte, como o famigerado "Minutos da Corte Suprema", que acabou por ganhar ares legislativos. Afinal, como fonte primordial do Direito Chinês, o Código Penal Chinês aparenta maior efetividade e unidade, mormente quando cotejado com documentos como o "Minutos".

Wuhan, 6 de maio de 2015.

\section{Referências}

CHINESE FOUNDATION FOR SOCIAL SCIENCE. The Legal Issues of International Law on the Transnational Corporate Offences, n. 08BFX074, Wuhan, 2011.

NATIONAL PEOPLE'S CONGRESS OF THE PEOPLE'S REPUBLIC OF CHINA. Criminal Law of the People's Republic of China. Disponível em: <http://law.npc.gov.cn:87/>. Acesso em: 3 de out. 2011.

JUNGONG, Sun. Some thinking about understanding and application of the Supreme Court interpretation on the specific issues related to the application of criminal law in hearing criminal cases involving crimes committed by a unit. Criminal Trial, v. 3, n. 3, p. 34-36, 1999. 
JUNGONG, Sun. Some thinking about Understanding and Application of the Supreme Court Interpretation on the Specific Issues Related to the Application of Criminal Law in Hearing Criminal Cases Involving Crimes Committed by a Unit. Criminal Trial, v. 3, n. 3, p. 34-36, 1999.

SUPREME COURT OF THE PEOPLE'S REPUBLIC OF CHINA. Supreme Court Interpretation on the Specific Issues Related to the Application of Criminal Law in Hearing Criminal Cases Involving Crimes Committed by Units. Interpretation 17/1999.

SUPREME COURT OF THE PEOPLE'S REPUBLIC OF CHINA. Supreme Court Interpretation on the Specific Issues Related to the Application of Criminal Law in Hearing Criminal Cases Involving Crimes Committed by Units. Interpretation 31/2000. 
